\title{
Bidirectionality and transcriptional activity of the EWSRI promoter region
}

\author{
EMELY MÖLLER $^{1}$, NILS MANDAHL ${ }^{1}$, MARIOLA ILISZKO ${ }^{2}$, \\ FREDRIK MERTENS $^{1}$ and IOANNIS PANAGOPOULOS ${ }^{1}$ \\ ${ }^{1}$ Department of Clinical Genetics, Lund University Hospital, SE-221 85 Lund, Sweden; \\ ${ }^{2}$ Department of Biology and Genetics, Medical University of Gdansk, Debinki 1, 80-210 Gdansk, Poland
}

Received August 28, 2008; Accepted October 15, 2008

DOI: $10.3892 /$ or_00000267

\begin{abstract}
EWSR1 is involved in chimeric proteins which play crucial roles in the development of a variety of bone and soft tissue tumors. Many of the chimeric genes involving EWSRl have been extensively studied, whereas less is known about the wild-type (wt) gene and its regulation. As the expression of the chimeric gene is driven by the EWSRI promoter, it is of importance to study the mechanisms regulating wt EWSRI expression. We estimated the transcriptional activity of the EWSR 1 promoter through deletion fragments driving reporter gene expression. This assay identified the 100-bp region immediately downstream of the EWSRI transcriptional start site $(+1)$ and the downstream region from +100 to +300 as important regions for transcriptional regulation. We also found that EWSR 1 and $R H B D D 3$, a gene located directly upstream of EWSR 1 that is likely to share regulatory elements with EWSRI, were co-expressed in the tissue panels, Ewing tumor biopsies and cell lines. Thus, our results show that the EWSR1 promoter functions in a bidirectional manner, thereby regulating also RHBDD3, and identifies specific regions that strongly influence promoter activity.
\end{abstract}

\section{Introduction}

The structurally and functionally related TET family of RNA-binding proteins includes EWSR1, FUS, TAF15, the fruitfly protein CAZ and the Zebrafish proteins EWSR1A and EWSR1B (1-5). These proteins are characterized by ArgGly-Gly (RGG)-repeats in the carboxy $(\mathrm{COOH})$-terminal part, an RNA-binding domain in the central region with a $\mathrm{Cys}_{2} /$ $\mathrm{Cys}_{2}$-type zinc finger motif on the 3'-side and a Ser-Tyr-GlyGln-Gln-Ser (SYGQQS) repeat-rich region in the amino

Correspondence to: Dr Emely Möller, Department of Clinical Genetics, Lund University Hospital, SE-221 85 Lund, Sweden E-mail: emely.moller@med.lu.se

Key words: EWSR1, RHBDD3, promoter, luciferase assay, Ewing sarcoma, bidirectionality
$\left(\mathrm{NH}_{2}\right)$-terminal part. In humans, the latter is known to function as a transcriptional activation domain and has been involved in a variety of chimeras associated with cancer (6-8). The TET proteins have been found to interact with distinct TFIID subpopulations, RNA polymerase II and proteins of the splicing machinery, indicating a role in transcription initiation and elongation as well as mRNA processing (reviewed in ref. 9).

Of the TET family members, EWSRl is the gene most often found in neoplasia-associated fusions. The most extensively studied example is EWSRI-FLII which is created by the $\mathrm{t}(11 ; 22)(\mathrm{q} 24 ; \mathrm{q} 12)$ present in $>85 \%$ of Ewing sarcoma family tumors $(3,10)$. Fusions involving EWSRl result in the formation of aberrant transcription factors through replacing the RNA-binding portions of EWSR1 with the COOH-terminal DNA-binding domain of the fusion partner. The ultimate consequence of the fusion is believed to be transcriptional deregulation of genes targeted by the transcription factor.

Since the expression of the chimeric gene is driven by the EWSRl promoter, it is important to understand the mechanisms regulating the wild-type (wt) EWSRl expression. However, little is known about the EWSRI promoter, apart from the genomic sequence 600-bp upstream of the initiator ATG codon studied by Plougastel et al (11). This GC-rich region contained several putative transcriptional start sites, whereas it lacked consensus TATA or CCAAT sequences, thus resembling the promoters of housekeeping genes (11).

We extended the analysis of the EWSRI regulatory region to include $\sim 2 \mathrm{kbp}$ and assayed the transcriptional activity of this region through measuring the ability of deletion constructs to drive the expression of the firefly luciferase gene. As bioinformatic analysis suggests that the EWSRI promoter is bidirectional, we also estimated the relative expression of EWSR1 and RHBDD3 (also called PTAG), a gene which is located directly upstream of EWSR1. EWSR1 (accession no. NM_005243) and RHBDD3 (NM_012265) are oriented headto-head with their transcriptional start sites situated within $400 \mathrm{bp}$ of each other, and are thus likely to share regulatory elements.

\section{Materials and methods}

Bioinformatic analyses. The EWSR1 5'-flanking region (part of the sequence with accession no. Y08806) chosen for the 
Table I. The sequences and combinations of primers used for the construction of reporter gene constructs.

\begin{tabular}{|c|c|c|}
\hline Primer name & Sequence $\left(5^{\prime} \rightarrow 3^{\prime}\right)$ & Fragment (primer combination) \\
\hline EWSprom49F & agctggtcccagctttggccetca & Template \\
\hline EWSprom2222R & gggaggcctcacagggacagcagc & Template \\
\hline EWSprom169F-KpnI & tggtcaggtacctctcggtcccagg & $\begin{array}{l}\text { pE1 }(169 \mathrm{~F}-K p n \mathrm{I}+1721 \mathrm{R}-B g l \mathrm{II}) \\
\text { pE2 }(169 \mathrm{~F}-K p n \mathrm{I}+1811 \mathrm{R}-B g l \mathrm{II}) \\
\text { pE3 }(169 \mathrm{~F}-K p n \mathrm{I}+2156 \mathrm{R}-B g l \mathrm{II})\end{array}$ \\
\hline EWSprom964F-KpnI & gtagggggtacccaggatctgtctg & $\begin{array}{l}\text { pE4 }(964 \mathrm{~F}-K p n \mathrm{I}+1721 \mathrm{R}-B g l \mathrm{II}) \\
\text { pE5 (964F-KpnI + 1811R-BglII }) \\
\text { pE6 (964F-KpnI + 2156R-BglII) }\end{array}$ \\
\hline EWSprom1324F-KpnI & cacacccggtaccgcgtgacc & $\begin{array}{l}\text { pE7 (1324F-KpnI + 1721R-BglII }) \\
\text { pE8 (1324F-KpnI + 1811R-BglII }) \\
\text { pE9 (1324F-KpnI + 2156R-BglII })\end{array}$ \\
\hline EWSprom1721R-BglII & cgcaggcgcaagatctcgcaa & $\mathrm{pE} 1, \mathrm{pE} 4, \mathrm{pE} 7$ \\
\hline EWSprom1811R-BglII & caccagatctcacccgtggacgcc & $\mathrm{pE} 2, \mathrm{pE} 5, \mathrm{pE} 8$ \\
\hline EWSprom2156R-BglII & tggecaagatctccecttcacgc & pE3, pE6, pE9 \\
\hline EWSprom1324F-BglII & cacacccgagatctcgcgtgacc & $\begin{array}{l}\text { p7Erev (1324F-BglII + 1721R-KpnI) } \\
\text { p9Erev (1324F-BglII + 2156R-KpnI) }\end{array}$ \\
\hline EWSprom1721R-KpnI & gcaggcgcaaaggtacctcgcaa & p7Erev \\
\hline EWSprom2156R-KpnI & tggccaaaggtacctcccettcac & p9Erev, p10Erev \\
\hline EWSprom1427F-BglII & ctcccgecagatctccgtctc & p10Erev (1427F-BglII + 2156R-KpnI) \\
\hline
\end{tabular}

present study extends roughly 1600-bp upstream to 400-bp downstream of the EWSRI transcriptional start site (accession no. X66899) (11). The CpG-content of the region was estimated with the CpGPlot software [(12), http://www.ebi. ac.uk/Tools/emboss/cpgplot/index.html]. The program GenomeVISTA [(13), http://genome.lbl.gov/vista/index.shtm] was used to search genome assemblies for candidate orthologous sequences to the EWSR1 5'-flanking region. The multiple sequence alignment was performed using the MultiAlin software [(14), http://bioinfo.genopole-toulouse.prd.fr/ multalin/multalin.html]. The weight-matrix based program Match public version (v) 1.0 (15) (cut-off selections; core similarity 0.8 , matrix similarity 0.8 , minimized sum of both error rates) and the pattern search program Patch public v 1.0 (both available at www.gene-regulation.com) (cut-off; 0 mismatches), were used to search for putative transcription factor binding sites (TFBSs) utilizing the TRANSFAC v 6.0 database. The weight-matrix based program MatInspector [(16), www.genomatix.de] which utilizes the MatBase database of TFBSs was also used for this purpose (cut-off selections; core similarity 0.8 , matrix similarity 0.8 ). Default settings were used for all analyses unless otherwise indicated.

Materials. The cell line HEK293 (human embryonic kidney, ICLC, Genova, Italy) and the human Ewing family tumor cell lines TC-71 (DSMZ no. ACC 516), SK-N-MC (DSMZ no. ACC 203), A-673 (ATCC no. CRL-1598), SK-PN-DW (ATCC no. CRL-2139), RH-1 (DSMZ no. ACC 493), MHH-ES-1
(DSMZ no. ACC 167), RD-ES (ATCC no. HTB-166), SKES-1 (ATCC no. HTB-86), SK-NEP-1 (ATCC no. HTB-48) and TTC-466 (kindly provided by Dr P.H. Sorensen, Vancouver) were used for transfection experiments and real-time PCR analysis. SK-N-MC cells have been described as derived from neuroblastoma, A-673 and RH-1 from rhabdomyosarcoma and SK-NEP-1 from Wilms tumor, but are now regarded as Ewing family tumor cell lines expressing the EWSRI-FLI1 fusion transcripts (17-19). Cells were cultured according to the suppliers' instructions with the additional supplements of $4 \mathrm{mM} \mathrm{L-glutamine,} 100$ units $/ \mathrm{ml}$ penicillin and $100 \mu \mathrm{g} / \mathrm{ml}$ streptomycin. Biopsy samples from four Ewing family tumors were also available for real-time PCR analysis.

RT-PCR analysis was performed on all the tumor samples and cell lines to confirm the presence of EWSR1-FLII type 1 or type 2 fusion transcripts. Total RNA was extracted from frozen tumor biopsies or cell lines using the TRIzol reagent (Invitrogen, Carlsbad, CA) and $2.5 \mu \mathrm{g}$ RNA was reverse transcribed in a $20 \mu 1$ reaction volume containing $1 \mathrm{X}$ Firststrand buffer (Invitrogen), $10 \mathrm{mM}$ DTT (Invitrogen), $0.5 \mathrm{mM}$ of each dNTP, $25 \mathrm{mM}$ random hexamers, 37 units of RNAguard (GE Healthcare Biosciences, Little Chalfont, UK) and 200 units of M-MLV reverse transcriptase (Invitrogen). The reaction was carried out at $37^{\circ} \mathrm{C}$ for $60 \mathrm{~min}, 70^{\circ} \mathrm{C}$ at $10 \mathrm{~min}$ and then kept at $4^{\circ} \mathrm{C}$. Nested PCR to detect EWSRI-FLII fusion transcripts was performed as described (20). PCR products were directly sequenced using the Big Dye terminator v1.1 cycle sequencing kit (Applied Biosystems, Foster City, 
CA) on an ABI-3100 Avant genetic analyzer (Applied Biosystems).

Construction of reporter gene plasmids. All the primer sequences are listed in Table I. The $2 \mathrm{kbp}$ EWSR1 5'-flanking region was amplified from $300 \mathrm{ng}$ DNA of the CTA-984G1 clone (accession no. A1031186) with AccuPrime P $f x$ PCR (Invitrogen) in a $50 \mu 1$ reaction volume of $1 \mathrm{X}$ AccuPrimeP $f x$ reaction mix, 1 unit of AccuPrimeP $x$ DNA polymerase and $0.3 \mu \mathrm{M}$ of each of the primers EWSprom $49 \mathrm{~F}$ forward and EWSprom2222R reverse. The PCR was run on a PCT-200 DNA Engine (MJ Research, Waltham, MA) with the cycling profile of an initial denaturation for $2 \mathrm{~min}$ at $95^{\circ} \mathrm{C}$ followed by 30 cycles of $15 \mathrm{sec}$ at $95^{\circ} \mathrm{C}, 30 \mathrm{sec}$ at $58^{\circ} \mathrm{C}$ and $2 \mathrm{~min}$ at $68^{\circ} \mathrm{C}$, and a final extension for $2 \mathrm{~min}$ at $72^{\circ} \mathrm{C}$. Serially truncated fragments of the $5^{\prime}$-flanking region; pE1-E9, p7E, p9E and p10E (Fig. 1A), were amplified as described above using the first amplified fragment as template and the primer combinations according to Table I. The fragments were then digested with the restriction endonucleases $B g l \mathrm{II}$ and $\mathrm{KpnI}$ and subcloned between the corresponding sites of the vector pFhRL. In pFhRL, the firefly and Renilla luciferase genes are transcribed in opposite directions and the expression of the internal control Renilla luciferase is driven by the SV40 early enhancer/promoter (21). Fragments p7Erev, p9Erev and p10Erev (Fig. 1B) were cloned in the reverse orientation. All ligations, DNA purifications and sequence verifications were performed as previously described (22).

Transfection and luciferase assays. The cell lines HEK293, TC-71, MHH-ES-1, RD-ES and TTC-466 were used for the transcriptional activation assay. Cells were seeded at a density of $2-5 \times 10^{4}$ cells/well in 96-well plates and $24 \mathrm{~h}$ later transfected with the test constructs pE1-E9. The PolyFect or Effectene transfection reagent (Qiagen, Valencia, CA) was used to transfect HEK293 cells with 0.5 or $0.1 \mu \mathrm{g}$ plasmid DNA, respectively, according to the manufacturers' instructions. TC-71, MHH-ES-1 and TTC-466 cells were transfected using the FuGENE HD transfection reagent (Roche Applied Sience, Indianapolis, IN) at the FuGENE $(\mu \mathrm{l})$ :DNA $(\mu \mathrm{g})$ ratio 5:2 (TC-71) or 6:2 (MHH-ES-1, RD-ES and TTC-466), according to the manufacturer's instructions. HEK293 and MHH-ES-1 cells were also transfected with the constructs p7Erev, p9Erev and p10Erev as described above. Empty plasmids were transfected together with the test constructs in each 96-well plate. The luciferase activity was quantified 24$48 \mathrm{~h}$ after transfection. The cell lysis and luciferase measurements were performed as previously described (21). Each construct was measured in at least eight replicas and the results are presented as median values together with the 25 th and 75th percentiles. The Mann-Whitney two-tailed test was used for the statistical analysis using the statistiXL software v 1.6 (http://www. statistixl.com).

Real-time PCR analysis. The TaqMan gene expression assays (Applied Biosystems) were used for the relative quantification of EWSR1 (Assay ID: Hs01580530) and RHBDD3 (Hs00925047) expression. RPLPO was used as an endogenous control to normalize for differences in sample cDNA input. Total RNA $(1 \mu \mathrm{g})$ was reverse transcribed as described above.
The PCR reaction was performed in a $20 \mu 1$ mixture containing $10 \mu 1$ 2X TaqMan universal PCR Mastermix (Applied Biosystems), $1 \mu 1$ 20X TaqMan Gene Expression mix and $1 \mu 1$ cDNA from all the tumor samples and cell lines available, as well as from the human MTC panels I and II (Clontech Laboratories, Mountain View, CA). Serial stock dilutions of A-673 cDNA were used to create standard curves for each assay on every reaction plate. All cDNAs were analyzed in triplicate. The PCR was run on an ABI 7500 real-time PCR system (Applied Biosystems) with the cycling profile of $2 \mathrm{~min}$ at $50^{\circ} \mathrm{C}, 10 \mathrm{~min}$ at $95^{\circ} \mathrm{C}$ followed by 50 cycles of $15 \mathrm{sec}$ at $95^{\circ} \mathrm{C}$ and $1 \mathrm{~min}$ at $60^{\circ} \mathrm{C}$. The input amounts of sample RNA were calculated from the A-673 standard curves and the results are presented as fold differences in gene expression levels between the test and calibrator samples.

\section{Results}

In silico analysis of the EWSR1 5'-flanking region. The 5 '-flanking region of EWSRl was found to have a high (>68\%) GC-content and a putative CpG-island, which covers the intergenic region between EWSRI and RHBDD3 and the first exons of both genes, was identified (Fig. 2A). The GenomeVISTA alignment of candidate orthologous sequences suggests that the 770-bp region encompassing the intergenic portion, the first exon of EWSRI and the sequence immediately downstream of it, has the highest sequence similarity across the species investigated. The more detailed multiple sequence alignment of the same region revealed smaller regions of high $(\geq 90 \%)$ or low $(\leq 50 \%)$ consensus sequence (Fig. 2 B). The number of putative TFBSs within the 770-bp sequence was narrowed down utilizing three different prediction programs. All three programs identified a potential MYBbinding site (MRE-element), four SP-1 sites (GC-, CA-, or CT-boxes), a YY1-binding site and an E-box (binding MYC, MAX or USF) (Fig. 2B). No apparent TATA- or CAAT-boxes were identified by these programs.

Transcriptional activity of the EWSR1 promoter region. HEK 293 cells and Ewing sarcoma cell lines expressing the EWSRIFLII type 1 (TC-71), EWSRI-FLII type 2 (MHH-ES-1) or EWSR1-ERG (TTC-466) fusion transcripts were used in this analysis. The fragments pE3, pE6 and pE9 had the lowest activities in all the cell lines $(\mathrm{P}<0.001)$ (Fig. 1A). In all cell lines except TC-71, fragments $\mathrm{pE} 2, \mathrm{pE} 5$ and $\mathrm{pE} 8$ activated the luciferase expression most efficiently $(\mathrm{P}<0.001)$. In TC-71 cells, no difference in activity was found between the $\mathrm{pE} 1$, pE2, pE4, pE5, pE7 and E8 fragments. Results obtained with RD-ES cells expressing the type 2 transcript (data not shown) are consistent with those obtained from MHH-ES-1, TTC466 and HEK293 cell transfections. The activities of fragments p7Erev, p9Erev and p10Erev (cloned in the reverse orientation) were also assessed. In MHH-ES-1 cells, the p10Erev fragment had the highest activity, followed by p9Erev, pE7 $(\mathrm{P}<0.001)$ and then pE9 and p7Erev. In HEK 293 cells, p10Erev had equally high activity as pE7 (Fig. 1B).

Gene expression by $R T-P C R$ and real-time PCR. In the EWSRI-FLII type 1 transcript, exon 7 of EWSRl is fused to exon 6 of FLII and in the type 2 transcript, the EWSRI exon 7 

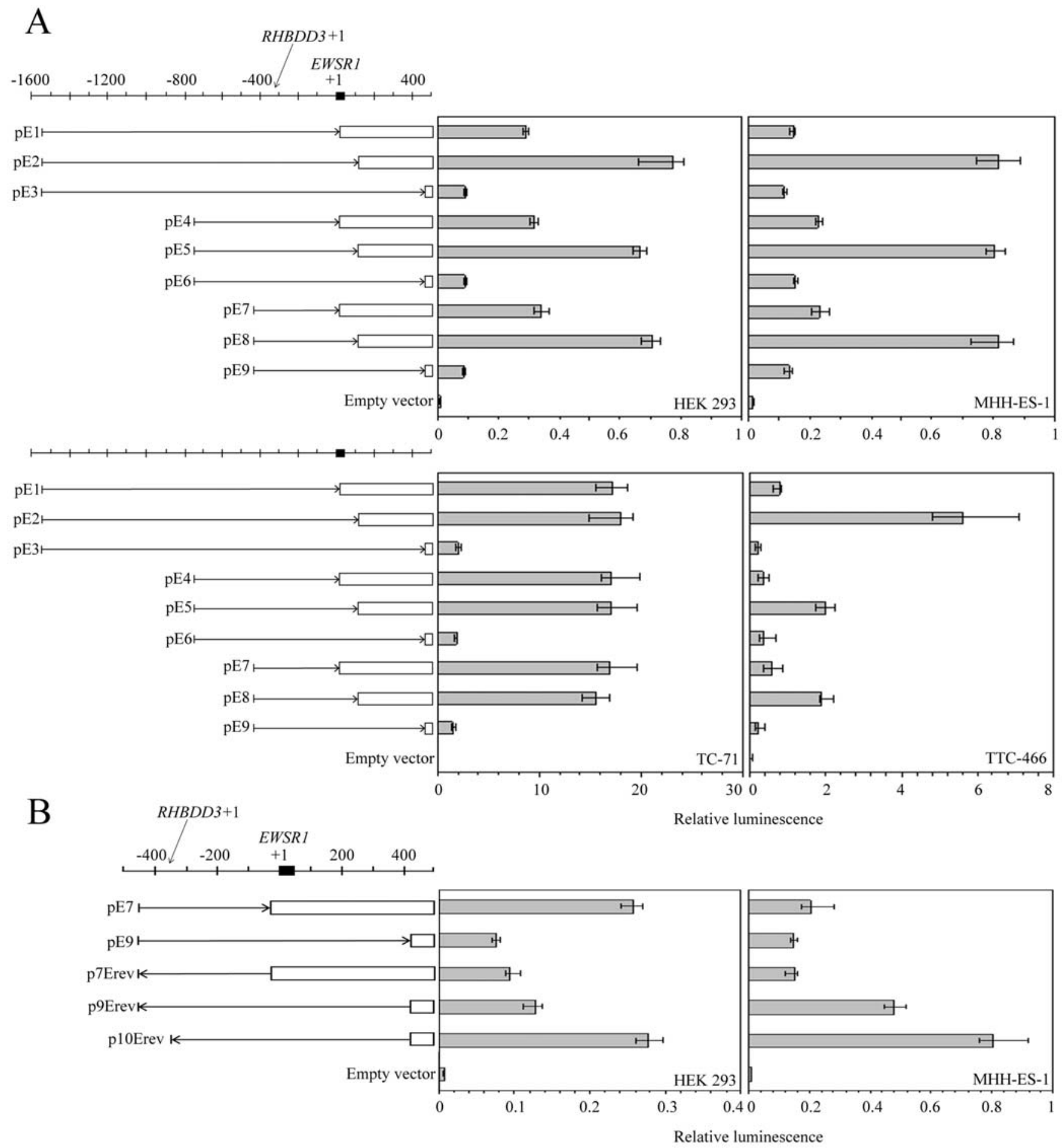

Figure 1. Transcriptional activity of the EWSR1 promoter fragment constructs. The promoter region investigated stretches from 1600-bp upstream, to 400-bp downstream, of the $E W S R 1+1$ site. Black boxes represent the translated region of $E W S R 1$ exon 1 . The position of the RHBDD3 +1 site is $369-$ bp upstream of the $E W S R 1+1$ site. The arrows represent the promoter fragments which were cloned upstream of the firefly luciferase gene (shown as white boxes) in the constructs. (A) The pE3, pE6 and pE9 fragments have the lowest promoter activity in all the cell lines. The pE2, pE5 and pE8 fragments have the highest activity in all the cell lines, except TC-71 (P<0.001). (B) The p10Erev fragment has high activity in both cell lines and the highest activity in MHH-ES-1 cells, whereas the pE9 and p7Erev fragments has the lowest activities $(\mathrm{P}<0.001)$. The p9Erev has higher activity than the corresponding $\mathrm{pE9}$ fragment in both cell lines, whereas the opposite relationship applies to p7Erev and $\mathrm{pE} 7$.

is fused to exon 5 of FLI1. The RT-PCR analysis confirmed the presence of type 1 EWSRI-FLII fusion transcripts in cell lines TC-71, SK-N-MC, A-673, SK-PN-DW and RH-1 cells, and type 2 transcripts in MHH-ES-1, RD-ES, SK-ES-1 and SK-NEP-1 cells. Cell line TTC-466 expresses the EWSRI$E R G$ fusion transcript. EWSRI-FLII type 1 transcripts were also found in three of the tumor biopsies and the type 2 transcript in one tumor.

The real-time PCR data show that the EWSRI promoter is active, and that the EWSRI and RHBDD3 genes are coexpressed, in both normal tissue panels (Fig. 3A) and Ewing biopsies and cell lines (Fig. 3B). 
A

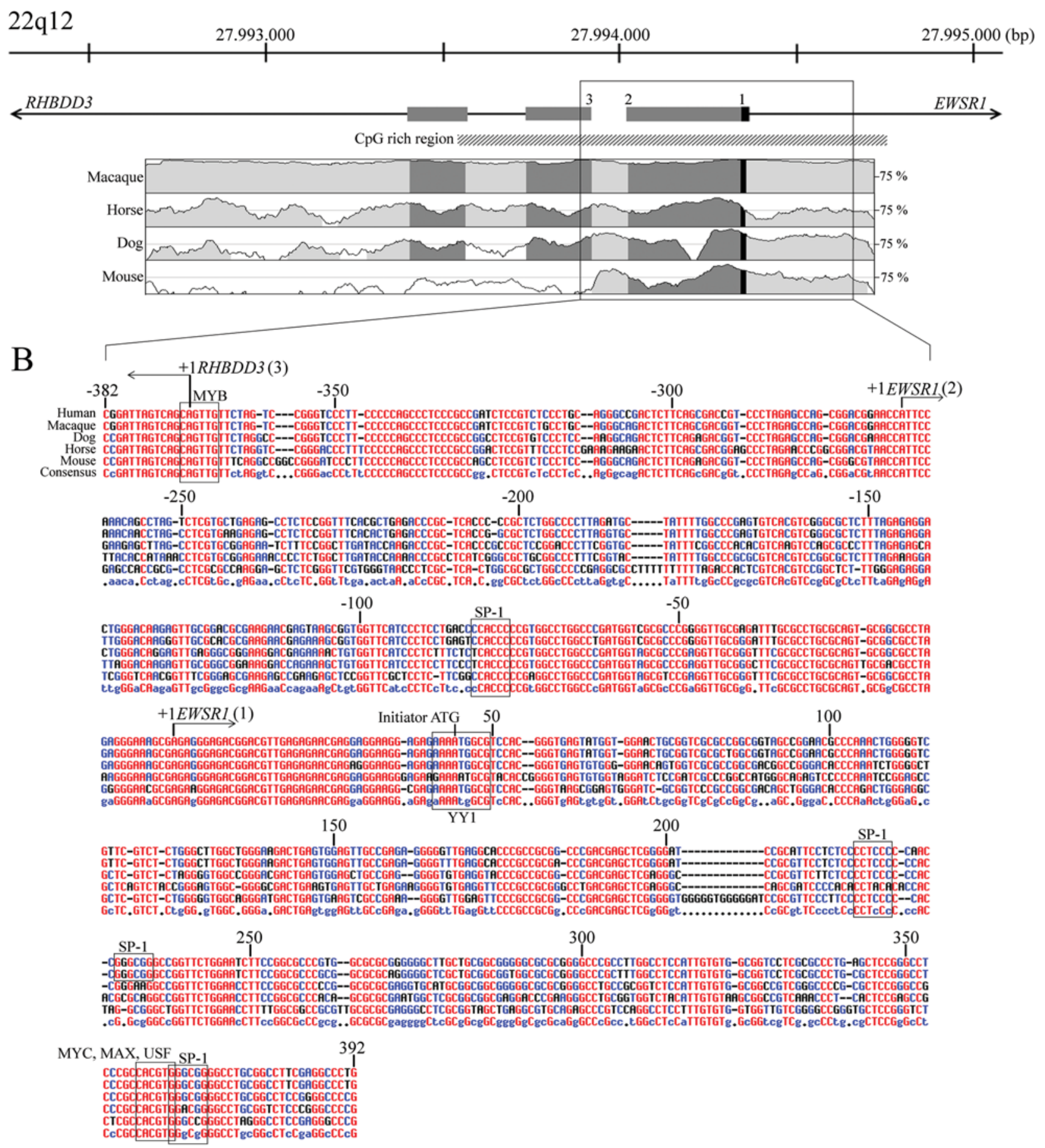

Figure 2. The organization of the genomic region surrounding the transcriptional start sites of the EWSR1 and RHBDD3. (A) Light grey areas represent non-coding regions, dark grey areas untranslated exons and black areas the translated region of EWSRI exon 1. The numbers 1-3 mark the +1 sites where 1) is the +1 site of EWSRI (accession no. X66899), 2) the alternative +1 site of EWSRI (accession no. DB051511) and 3) the +1 site of RHBDD3 (accession no. NM_012265). The striped box represents the CpG rich region identified by CpGPlot. The conservation plot is displayed as a continuous curve where greyscaled areas denote conserved ( $>70 \%$ sequence similarity) regions and white areas non-conserved regions. The most conserved region is indicated with a box. (B) Multiple sequence alignment of the most conserved 770-bp region. High consensus sequence $(\geq 90 \%)$ appears in red and low consensus ( $\leq 50 \%)$ in blue. In the consensus line, highly conserved residues appear in red and as uppercase letters, whereas weakly conserved residues appear in blue and as lowercase letters. Dots represent positions with no conserved residues. The putative TFBSs are indicated with boxes, all are conserved across species except for one of the SP-1 sites.

\section{Discussion}

Although EWSRl is well-known as the 5'-partner gene of numerous chimeras in human tumors, less is known about the gene itself and its regulation. Therefore, we investigated the regulatory region of EWSRI to delineate specific portions that prominently influence promoter activity. Moreover, the head-to-head arrangement of the EWSRI and RHBDD3 genes 


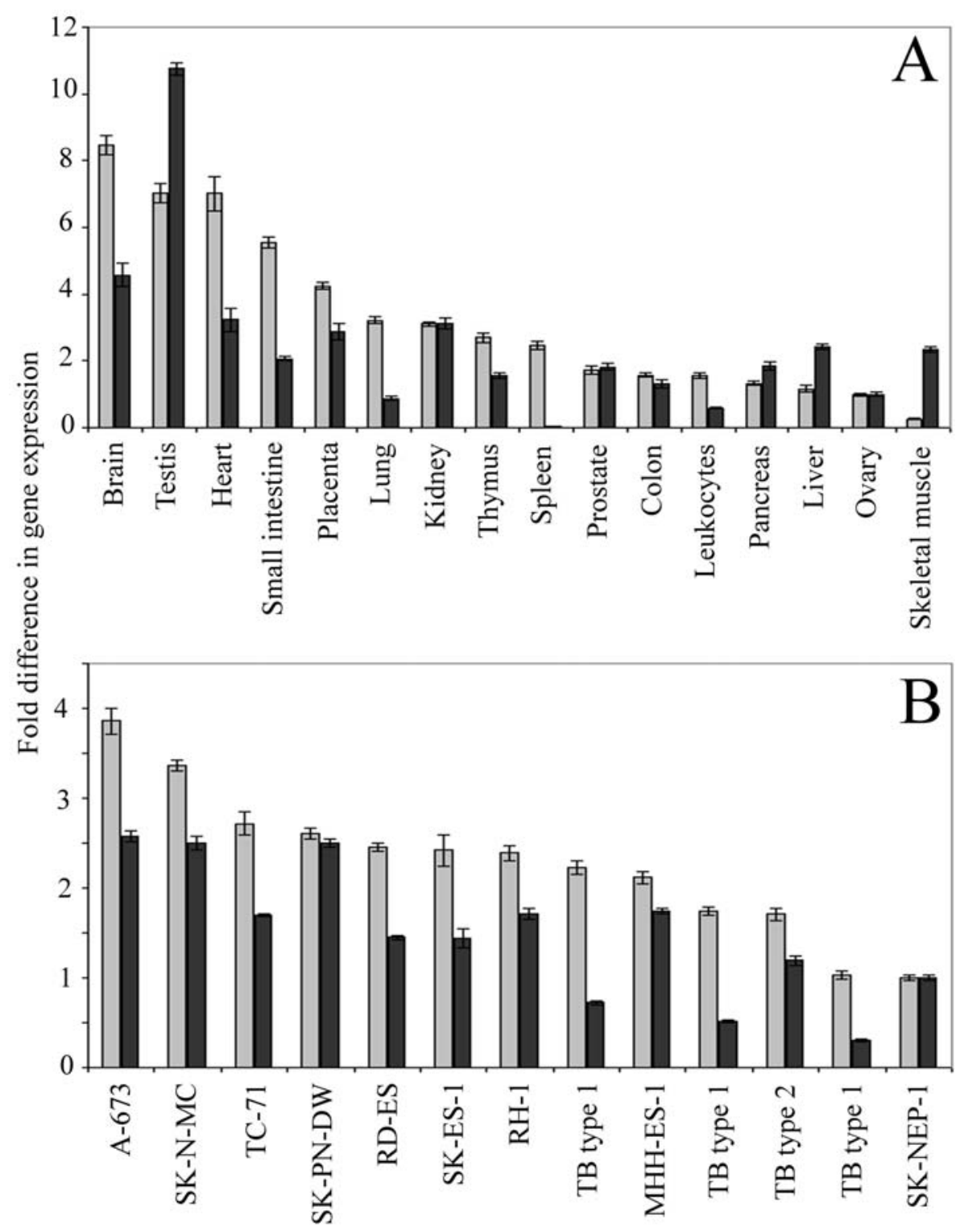

Figure 3. The relative expression levels of EWSR1 and RHBDD3. Expression values have been normalized to RPLPO and are presented as fold differences in expression levels relative to the calibrator sample (ovary or SK-NEP-1, respectively). Light grey bars represent the level of EWSR1 expression and the dark grey bars that of RHBDD3. (A) Co-expression of EWSR1 and RHBDD3 in normal tissue panels. (B) EWSR1 and RHBDD3 are co-expressed also in Ewing tumors and cell lines. TB denotes the tumor biopsy samples; the presence of type 1 or 2 EWSR1-FLII fusion transcripts is indicated.

with a short distance $(<400 \mathrm{bp})$ between their transcriptional start sites suggested to us that they may share a bidirectional promoter region. Thus, we also investigated the bidirectional activity of the core promoter region and compared the relative gene expression levels of EWSRI and RHBDD3 in tissue panels and Ewing tumor biopsies and cell lines.

The results from the transcriptional activation assay show that deleting different parts of the sequence from -1600 to -440 had little effect on the promoter activity. In contrast, deleting parts of the -440 to +400 portion had a considerable effect on activity, indicating that this region is important for transcriptional activity. The fact that it encompasses the transcriptional start sites of both EWSR1 and RHBDD3, together with the high degree of sequence similarity across species observed for this area, further implies an important role in regulation. The fragments containing the entire -440 to +400 portion (pE3, pE6 and pE9) had the lowest activities in all the cell lines, presumably because this specific region recruits negatively acting transcription factors. Deletion of the +65 to +400 part (fragments $\mathrm{pE} 2, \mathrm{pE} 5$ and $\mathrm{pE} 8$ ) notably increased activity. The $\mathrm{pE} 2, \mathrm{pE} 5$ and $\mathrm{pE} 8$ fragments had the highest activities in all cell lines used, except TC-71. The deleted part contains three putative binding sites for transcription factors of the SP-family and an E-box recognized by factors such as MYC, MAX and USF. Particularly the SP factors have been associated with the regulation of housekeeping genes and GC-rich promoters (23).

Further deletion of the 90 bp portion immediately downstream of the EWSRI +1 site (fragments pE1, pE4 and pE7) decreased promoter activity, except in TC-71 cells. These activities were less than half of those achieved by the fragments retaining the 90 -bp portion, indicating that this narrow region 
is important for transcriptional activation and most likely also for transcriptional initiation, due to its position close to the +1 site. This region contains a putative binding site for YY1, a ubiquitously expressed transcription factor which may act indirectly or directly to activate or repress gene expression (24). In TC-71 cells, the deletion had no effect on activity, suggesting cell-specific regulation depending on distinct transcription factor content.

The experiment with the fragments cloned in the reverse orientation (p7Erev, p9Erev and p10Erev) shows that the promoter region is capable of bidirectional activity, although to some degree in a cell-specific manner. It is noteworthy that in contrast to the above-mentioned results from the transcription activation assay, p9Erev which contains the entire -440 to +400 portion activated transcription more effectively than the p7Erev fragment. Fragment p10Erev differs from the others in that it only reaches to, and not downstream of, the $R H B D D 3+1$ site. It had high activity in both cell lines, implying an important role for the intergenic area upstream of the $R H B D D 3+1$ site. Furthermore, as shown by the real-time PCR data, EWSR 1 and RHBDD3 are co-expressed in tissue panels and Ewing tumors and cell lines. These results support the idea that these genes may be co-regulated by a common bidirectional promoter.

The bidirectional arrangement has previously been described for gene pairs arranged head-to-head on opposite strands with $<1 \mathrm{kbp}$ between their transcriptional start sites. Bidirectional promoters may be required to maintain a stoichiometric relationship between the gene products or for the co-expression of genes involved in the same pathway. Moreover, bidirectionality has been associated with a higher GC-content compared to non-bidirectional promoters. A $\mathrm{CpG}$-island is often found between the start sites of the genes which also overlaps the first exons of each gene $(25,26)$. The latter is true also for the region shared by EWSRI and $R H B D D 3$. RHBDD3 was originally identified as a proapoptotic gene with decreased expression in pituitary tumors. Loss of expression was associated with methylation of its CpG island (27). Recently, loss of RHBDD3 expression was found in 16 out of 18 colorectal tumor samples. However, in this instance the tumors and normal colon had similar densities of CpG island methylation (28). The mechanism causing this loss of expression is currently unknown.

In conclusion, we have delineated specific regions of the EWSRI promoter that seem to be important for promoter function and provide evidence that the EWSRI promoter is capable of bidirectional activity. The regions we identified may be the subject of future studies which aim to characterize the transcription factor networks which are involved in the regulation of this gene (or rather, these genes). Moreover, the bidirectional activity raises questions concerning the mechanisms behind the loss of RHBDD3 expression in colorectal tumors and gene expression status of EWSR1 in these tumors.

\section{Acknowledgements}

This study was supported by the Swedish Children's Cancer Foundation, the Swedish Cancer Society, the Swedish Research Council, the Gunnar Nilsson's Cancer Foundation and the Lund University Hospital.

\section{References}

1. Azuma M, Embree LJ, Sabaawy H and Hickstein DD: Ewing sarcoma protein ewsr1 maintains mitotic integrity and proneural cell survival in the zebrafish embryo. PLoS ONE 2: E979, 2007.

2. Crozat A, Åman P, Mandahl N and Ron D: Fusion of CHOP to a novel RNA-binding protein in human myxoid liposarcoma. Nature 363: 640-644, 1993.

3. Delattre O, Zucman J, Plougastel B, Desmaze C, Melot T, Peter M, Kovar H, Joubert I, de Jong P, Rouleau G, Aurias A and Thomas G: Gene fusion with an ETS DNA-binding domain caused by chromosome translocation in human tumours. Nature 359: 162-165, 1992.

4. Morohoshi F, Arai K, Takahashi EI, Tanigami A and Ohki M: Cloning and mapping of a human RBP56 gene encoding a putative RNA binding protein similar to FUS/TLS and EWS proteins. Genomics 38: 51-57, 1996.

5. Stolow DT and Haynes SR: Cabeza, a Drosophila gene encoding a novel RNA binding protein, shares homology with EWS and TLS, two genes involved in human sarcoma formation. Nucleic Acids Res 23: 835-843, 1995.

6. Bertolotti A, Bell B and Tora L: The N-terminal domain of human $\mathrm{TAF}_{\mathrm{II}} 68$ displays transactivation and oncogenic properties. Oncogene 18: 8000-8010, 1999.

7. May WA, Lessnick SL, Braun BS, Klemsz M, Lewis BC, Lunsford LB, Hromas R and Denny CT: The Ewing's sarcoma $E W S / F L I-1$ fusion gene encodes a more potent transcriptional activator and is a more powerful transforming gene than FLI-1. Mol Cell Biol 13: 7393-7398, 1993.

8. Prasad DD, Ouchida M, Lee L, Rao VN and Reddy ES: TLS/ FUS fusion domain of TLS/FUS-erg chimeric protein resulting from the $\mathrm{t}(16 ; 21)$ chromosomal translocation in human myeloid leukemia functions as a transcriptional activation domain. Oncogene 9: 3717-3729, 1994.

9. Riggi N, Cironi L, Suva ML and Stamenkovic I: Sarcomas: genetics, signalling, and cellular origins. Part 1: The fellowship of TET. J Pathol 213: 4-20, 2007.

10. Turc-Carel C, Aurias A, Mugneret F, Lizard S, Sidaner I, Volk C, Thiery JP, Olschwang S, Philip I, Berger MP, Philip T, Lenoir GM and Mazabraud A: Chromosomes in Ewing's sarcoma. I. An evaluation of 85 cases and remarkable consistency of $t(11 ; 22)$ (q24;q12). Cancer Genet Cytogenet 32: 229-238, 1988.

11. Plougastel B, Zucman J, Peter M, Thomas G and Delattre O: Genomic structure of the EWS gene and its relationship to EWSR1, a site of tumor-associated chromosome translocation. Genomics 18: 609-615, 1993.

12. Larsen F, Gundersen G, Lopez R and Prydz H: CpG islands as gene markers in the human genome. Genomics 13: 1095-1107, 1992.

13. Couronne O, Poliakov A, Bray N, Ishkhanov T, Ryaboy D, Rubin E, Pachter L and Dubchak I: Strategies and tools for whole-genome alignments. Genome Res 13: 73-80, 2003.

14. Corpet F: Multiple sequence alignment with hierarchical clustering. Nucleic Acids Res 16: 10881-10890, 1988.

15. Kel AE, Gössling E, Reuter I, Cheremushkin E, KelMargoulis OV and Wingender E: MATCH: A tool for searching transcription factor binding sites in DNA sequences. Nucleic Acids Res 31: 3576-3579, 2003.

16. Cartharius K, Frech K, Grote K, Klocke B, Haltmeier M, Klingenhoff A, Frisch M, Bayerlein $M$ and Werner T: MatInspector and beyond: promoter analysis based on transcription factor binding sites. Bioinformatics 21: 2933-2942, 2005.

17. Dunn T, Praissman L, Hagag N and Viola MV: ERG gene is translocated in an Ewing's sarcoma cell line. Cancer Genet Cytogenet 76: 19-22, 1994.

18. Roberts I, Wienberg J, Nacheva E, Grace C, Griffin D and Coleman N: Novel method for the production of multiple colour chromosome paints for use in karyotyping by fluorescence in situ hybridisation. Genes Chromosomes Cancer 25: 241-250, 1999.

19. Smith MA, Morton CL, Phelps D, Girtman K, Neale G and Houghton PJ: SK-NEP-1 and Rh1 are Ewing family tumor lines. Pediatr Blood Cancer 50: 703-706, 2008.

20. Panagopoulos I, Mertens F, Domanski HA, Isaksson M, Brosjö O, Gustafson P and Mandahl N: No EWS/FLII fusion transcripts in giant-cell tumors of bone. Int J Cancer 93: 769-772, 2001

21. Möller E, Isaksson M, Mandahl N, Mertens F and Panagopoulos I: Comparison of the proximal promoter regions of the $P A X 3$ and PAX7 genes. Cancer Genet Cytogenet 178: 114-119, 2007. 
22. Panagopoulos I, Möller E, Dahlén A, Isaksson M, Mandahl N, Vlamis-Gardikas A and Mertens F: Characterization of the native CREB3L2 transcription factor and the FUS/CREB3L2 chimera. Genes Chromosomes Cancer 46: 181-191, 2007.

23. Wierstra I: Sp1: Emerging roles - beyond constitutive activation of TATA-less housekeeping genes. Biochem Biophys Res Commun 372: 1-13, 2008.

24. Gordon S, Akopyan G, Garban H and Bonavida B: Transcription factor YY1: structure, function, and therapeutic implications in cancer biology. Oncogene 25: 1125-1142, 2006.

25. Adachi $\mathrm{N}$ and Lieber MR: Bidirectional gene organization: a common architectural feature of the human genome. Cell 109: 807-809, 2002.
26. Trinklein ND, Aldred SF, Hartman SJ, Schroeder DI, Otillar RP and Myers RM: An abundance of bidirectional promoters in the human genome. Genome Res 14: 62-66, 2004.

27. Bahar A, Simpson DJ, Cutty SJ, Bicknell JE, Hoban PR, Holley S, Mourtada-Maarabouni M, Williams GT, Clayton RN and Farrell WE: Isolation and characterization of a novel pituitary tumor apoptosis gene. Mol Endocrinol 18: 1827-1839, 2004.

28. Bahar A, Whitby P, Holley S, Hoban PR, Elder JB, Deakin M, Hall C, Clayton RN, Williams GT and Farrell WE: Primary colorectal tumors fail to express the proapoptotic mediator PTAG and its reexpression augments drug-induced apoptosis. Genes Chromosomes Cancer 46: 202-212, 2007. 